As Parcerias Público-Privadas na Europa e em Portugal

Rosário Garcia Gomes

Abril 2018

WP n. $2018 / 04$

DOCUMENTO DE TRABALHO

WORKI NG PAPER

DINAMIR'CET

CENTRO DE ESTUDOS SOBREA MUDANÇA
SOCIOECONOMICA E O TERAITARID

ISCTE-IUL

ISCTE IUL

Instituto Universitário de Lisboa

FCT

Fundasho para a Ciencia e e Tecoologia 


\title{
As Parcerias Público-Privadas na Europa e em Portugal
}

\author{
Rosário Garcia Gomes ${ }^{1,2}$ \\ WP n. 0 2018/04
}

DOI: $10.15847 /$ dinamiacet-iul.wp.2018.04

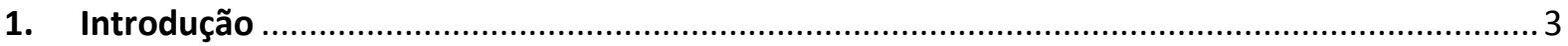

2. O outsourcing e as parcerias público-privadas - definições e enquadramento …..................... 3

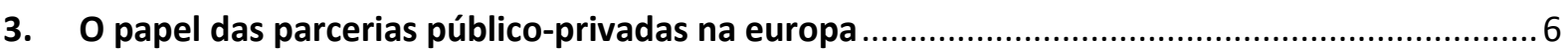

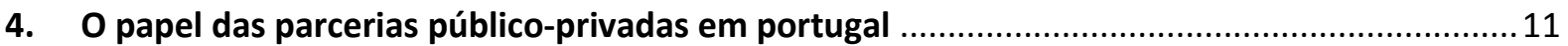

6. Parcerias público-privadas - o que correu mal em portugal ....................................................16

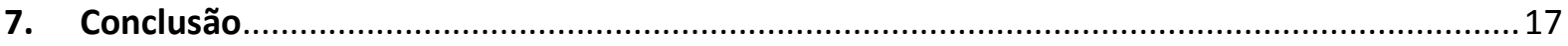

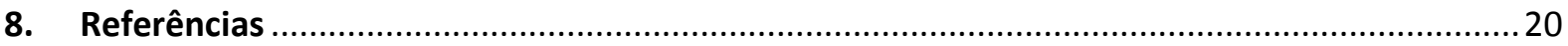

\footnotetext{
${ }^{1}$ A autora agradece as sugestões do revisor anónimo do Dinâmia'CET, que foram muito úteis e contribuíram para melhorar este Working Paper.

2 Doutoranda em Políticas Públicas pelo ISCTE-IUL; Mestre em Ciências do Trabalho e Relações Laborais, pelo ISCTE-IUL e licenciada em gestão pelo ISEG.
} 


\section{As Parcerias Público-Privadas na Europa e em Portugal}

\section{RESUMO}

Tendo em vista o crescimento do número de Parcerias Público-Privadas que teve lugar nos finais do século XX e primeira década do século XXI, quer na Europa, quer em Portugal, pretende-se com este estudo analisar o debate sobre o papel, por vezes polémico, desempenhado por estas formas de contratação no contexto internacional de crise e de contenção da despesa pública. Duas questões fulcrais são colocadas em sede de debate: as Parcerias Público-Privadas contribuíram para a redução da despesa pública? Verificou-se, ou não, degradação na qualidade do serviço público? Será analisada a definição de Parceria Público-Privada, enquadrada no conceito mais lato de outsourcing, e identificado o enquadramento histórico-económico e político em que assentou o crescimento desta forma de contratação no âmbito dos serviços públicos, quais os objetivos a que se propunha e se estes objetivos foram atingidos nas perspetivas financeira e social. Por último, serão detalhados e analisados os riscos associados à utilização desta forma de contratação. 


\section{INTRODUÇÃO}

O objetivo deste estudo consiste na análise do papel desempenhado pelas Parcerias Público-Privadas na Europa do século XXI, no contexto internacional de crise e da contração da despesa pública por parte dos Governos, assim como na procura de evidências sobre se esta forma de contratação contribui para a redução da despesa pública e se garante a qualidade do serviço público prestado ao cidadão. Será analisado genericamente o caso da Europa e, de forma mais detalhada, o caso português. Através de evidências empíricas, será mostrado que nos últimos anos as Parcerias PúblicoPrivadas têm vindo a crescer de forma quase exponencial na Europa e também em Portugal. Começarse-á por analisar a definição de Parceria Público-Privada e por enquadrar esta definição no conceito mais lato de outsourcing, identificando-se o enquadramento histórico-económico e político em que foi alicerçado o crescimento desta forma de contratação no âmbito da prestação de serviços públicos, passando para o retrato das correntes e dos debates dos autores que têm abordado este tema na literatura técnica e académica nos últimos anos, concluindo-se com a apresentação de alguns dados empíricos para a situação europeia. Seguidamente será caracterizado o caso das Parcerias PúblicoPrivadas em Portugal com dados empíricos e analisado o debate dos autores que se debruçaram sobre o caso português das Parcerias Público-Privadas, será apresentada uma breve resenha sobre os aspetos negativos e o que pode correr mal nesta forma de contratação, após o que será apresentada a conclusão. A análise do caso português será efetuada com base em estudos existentes. A análise dos dados empíricos e a literatura existente mostrará que não há indícios claros sobre a contratação efetuada através de Parcerias Público-Privadas ter gerado poupanças nas despesas públicas, podendo até apontar para o aumento dessas despesas, e que existem poucos indicadores ou outros dados empíricos que comprovem com clareza se a qualidade dos serviços públicos foi comprometida nestes processos. No entanto, ficou claro que os riscos e as preocupações associados a esta forma de contratação são muitos e terão reflexos nas finanças públicas da próxima geração.

\section{O OUTSOURCING E AS PARCERIAS PÚblico-PRIVAdas - DEFINIÇÕES E ENQUADRAMENTO}

Existem diversas definições na literatura técnica e na literatura académica para os conceitos de Parceria Público-Privada e outsourcing. No dicionário de Cambridge, a definição de outsourcing é a de "uma situação na qual uma empresa contrata uma outra empresa para fazer uma parte do seu trabalho, em vez de utilizar os seus próprios trabalhadores para o fazer". ${ }^{3}$ A OCDE define outsourcing, como sendo a "delegação de parte das atividades a um fornecedor externo". Por vezes também é usado como sinónimo de outsourcing o termo offshoring. Contudo, o significado de ambos

\footnotetext{
3 "A situation in which a company employs another organization to do some of its work, rather than using its own employees to do it", http://dictionary.cambridge.org/pt/dicionario/ingles/outsourcing, consultado em 12 de janeiro de 2016.

\author{
DINÂMIA'CET - IUL, Centro de Estudos sobre a Mudança Socioeconómica e o Território \\ do Instituto Universitário de Lisboa (ISCTE-IUL) \\ Sala 2W4 - D | ISCTE-IUL - Av. das Forças Armadas \\ 1649-026 Lisboa, PORTUGAL
}


os termos consiste na aquisição de serviços a uma entidade terceira, ou a um fornecedor. ${ }^{4}$ Marzetti (2006) entende que a definição de outsourcing é pouco clara, reunindo um conjunto de definições atribuídas por outros autores. Por exemplo, Van Mieghem (1999) define a relação entre o contratante e o fornecedor onde o primeiro está inteiramente dependente do segundo, por não deter a capacidade de prestar os serviços contratados (capacidade do contratante). Por sua vez, Grossman e Helpman (2005) e Leimbach (2005) entendem que o outsourcing é uma situação na qual uma empresa estabelece uma relação bilateral com outra entidade, com o objetivo de levar a cabo atividades necessárias para um determinado investimento (natureza das atividades).

Seguindo algumas pistas apontadas por estas definições de outsourcing, como por exemplo "contratar a terceiros" ou "relação bilateral", pode-se estabelecer uma ligação com a definição de Parceria Público-Privada. Numa apresentação de 2009 da IAOP , encontra-se uma associação entre outsourcing e Parceria Público-Privada, onde se define uma Parceria Público-Privada como uma forma de outsourcing, diferenciada desta última pela complexidade dos seus contornos, pela forma de financiamento e pela estrutura contratual. O Livro Verde da União Europeia sobre as Parcerias Público-Privadas define o conceito de PPP como “(...)uma expressão que se refere, em geral, a formas de cooperação entre as autoridades públicas e as empresas, tendo por objectivo assegurar o financiamento, a construção, a renovação, a gestão ou a manutenção de uma infra-estrutura ou a prestação de um serviço" ${ }^{\circ}$. Miranda Sarmento, no seu ensaio de $2013,{ }^{7}$ define o conceito de Parcerias Público-Privadas pela via jurídico-económica como uma forma de “( ...)contrato entre o sector público e uma entidade privada, "de acordo com requisitos definidos no contrato" para prestação de um serviço que será remunerado." (Sarmento, 2013). No meu entender, a esta definição falta o elemento temporal da durabilidade do contrato e que constitui uma das complexidades desta forma de aquisição de serviços, pois o elemento de duração do contrato poderá envolver um conjunto de situações ou consequências que perderiam a sua relevância a curto ou médio prazo.

A definição de Hemming (2006) para Parceria Público-Privada assenta na negociação onde o setor privado fornece um bem de infraestrutura e presta um serviço associado a essa infraestrutura que, tipicamente faziam parte da ação governamental. Esta definição introduz um novo conceito de "infraestrutura", desvendando uma tipificação a um conceito inicialmente agregador de Parceria Público-Privada. Weihe (2006) desvenda essa tipificação, indicando que diversos autores podem utilizar o conceito de Parceria Público-Privada com diferentes significados e cita a definição de Van

\footnotetext{
4 https://stats.oecd.org/glossary/detail.asp?ID=4950, glossário de termos estatísticos da OCDE, consultado em 11 de janeiro de 2016.

${ }^{5}$ IAOP (International Association of Outsourcing Professionals), "Outsourcing and Private Public Partnerships", The 2009 Outsourcing World Summit, apresentação da SNC_Lavalin Pro-Fac, por Jean-François Poisson.

${ }^{6}$ Livro verde sobre as parcerias público-privadas e o direito comunitário em matéria de contratos públicos e concessões, COM (2004), 327 Final, Bruxelas, 30/04/2004.

7 "Parcerias Público-Privadas" de Joaquim Miranda Sarmento, 2013, editado pela Fundação Francisco Manuel dos Santos.
} 
Ham e Koppenjan (2001:598), como sendo uma definição utilizada amiúde, de uma cooperação com alguma durabilidade entre os setores público e privado no qual ambos desenvolvem em conjunto produtos e serviços e partilham riscos, recursos e custos associados a esses produtos ${ }^{8}$. Weihe identifica cinco distinções qualitativas na abordagem das Parcerias Público-Privadas existentes na literatura, que para o autor são cruciais na clareza da análise do papel destas formas de contratação e na identificação dos problemas e benefícios associados à sua utilização:

(1) A abordagem política, que utiliza o conceito de Parceria Público-Privada como sinónimo de um conjunto de relações, mais ou menos alargadas, de caráter público-privado no âmbito de um determinado setor de atividade;

(2) A abordagem económica, associada ao desenvolvimento económico de uma zona geográfica;

(3) A abordagem do conceito de infraestrutura, que utiliza o conceito de Parceria Público-Privada como sinónimo de projetos de investimento privado relacionados com a construção de infraestruturas às quais estão associados serviços de arquitetura, construção, operação e manutenção, entre outros;

(4) A abordagem governamental, que se aproxima à abordagem política mas introduzindo o fator de governança na gestão da Parceria Público-Privada, encadeando-se este tema nos conceitos de New Public Management e de modernização administrativa que tem vindo a ser debatido nas últimas décadas. Esta abordagem considera um amplo envolvimento do setor privado na gestão pública no que respeita à produção e prestação de serviços públicos através da contratação de parcerias estratégicas ou da concessão de atividades que, historicamente, eram detidas pelas administrações públicas;

(5) A abordagem do desenvolvimento, na qual as Parcerias Público-Privadas surgem como entidades que capacitam o desenvolvimento em países menos desenvolvidos.

Ao longo deste estudo veremos que a abordagem mais utilizada pelos autores é a do conceito de infraestrutura.

Para Weihe, a expressão Parceria Público-Privada serve apenas para revelar uma relação público-privada entre atores públicos e privados que tem lugar numa determinada área de intervenção pública. A esta definição acrescentarei os fatores de contratação e de temporalidade e passarei a utilizar este conceito ao longo deste estudo.

\footnotetext{
8 "...cooperation of some sort of durability between public and private actors in which they jointly develop products and services and share risks, costs and resources which are connected with these products" (Van Ham \& Koppenjan, 2001:598).
} 


\section{O PAPEL DAS PARCERIAS PÚBLICO-PRIVADAS NA EUROPA}

De acordo com o Livro Verde sobre as Parcerias Público-Privadas, publicado em 2004, este fenómeno tem vindo a desenvolver-se na Europa desde finais do século XX em diversas áreas de tradicional competência do setor público, o que pode ser explicado por variados fatores:

(1) As restrições orçamentais com que se deparam os Estados-Membros da União Europeia, que conduzem à necessidade de atração de financiamentos privados para o setor público;

(2) A vontade das administrações públicas em beneficiarem dos modos de funcionamento e da experiência do setor privado no âmbito da participação pública;

(3) A modificação do papel do Estado na esfera económica, que tem vindo gradualmente a passar do papel de prestador direto para o papel de organizador, regulador e fiscalizador tem promovido o desenvolvimento das Parcerias Público-Privadas;

(4) A aprovação de uma série de medidas por parte do Conselho Europeu no âmbito da Iniciativa para o Crescimento teve em vista o aumento dos investimentos nas infraestruturas da rede transeuropeia e no domínio da investigação, do desenvolvimento e da inovação através da constituição de Parcerias Público-Privadas .

Para Weihe (2006), o ponto de viragem para o aumento de interesse dos governos pelas Parcerias Público-Privadas deu-se em finais da década de 90 e no início do século XXI com a iniciativa de financiamento privado levada a cabo pelo Governo do Reino Unido. Também Hemming (2006) refere o caso do Reino Unido como sendo o mais desenvolvido em matéria de Parcerias Público-Privadas e onde a Iniciativa de Investimento Privado ${ }^{10}$ teve início em 1992, detendo atualmente $14 \%$ dos investimentos públicos em áreas-chave. Na opinião de Hemming (2006), as Parcerias PúblicoPrivadas são vantajosas tanto para o governo como para o setor privado e estão estabelecidas em programas nalguns países mais avançados da OCDE. Para este autor, o financiamento dos investimentos elevados e de longa duração, assim como a futura obtenção de receitas para o governo, a gestão eficaz do parceiro privado e a sua capacidade de inovar são qualidades que conduzem ao acréscimo da eficiência. Estes fatores levam a um aumento na qualidade e / ou à redução dos custos dos serviços. Assim, o autor defende que as Parcerias Público-Privadas são uma boa forma de rentabilizar os recursos financeiros públicos. Para o setor privado, a parceria oferece também boas oportunidades de negócio em áreas tradicionalmente operadas pelo Estado. O autor ressalva que existem algumas condições para se garantir uma parceria de sucesso. Por exemplo, o governo deverá definir indicadores de medição de qualidade dos serviços, ligando os pagamentos dos contratos com o cumprimento dos níveis de qualidade acordados. Outra condição reside na existência de competitividade do mercado ou na existência de regulação que promova o incentivo a operar naquele

\footnotetext{
${ }^{9}$ Conclusões da Presidência, Conselho Europeu de Bruxelas de 12 de Dezembro de 2003.

${ }^{10}$ PFI - Private Finance Initiative.

DINÂMIA'CET - IUL, Centro de Estudos sobre a Mudança Socioeconómica e o Território 
mercado, o que dificilmente acontece na construção de infraestruturas, onde a tendência é para a existência de monopólio por parte do governo e onde a partilha do lucro e a transferência de risco adequada deverão ser formas de regulação existentes para a proteção dos parceiros.

Engel, Fischer e Galetovic (2010) defendem a utilização de Parcerias Público-Privadas e apontam como argumento funcionalista o racionalismo desta forma de contratação, assim como o contributo que poderá dar a uma melhor utilização de recursos (Engel et al., 2010). Para os autores, as características económicas e financeiras dos projetos associados à construção e gestão de infraestruturas propiciam a utilização de parcerias entre o setor público e o estado, onde o parceiro privado asseguraria a capitalização inicial de projetos de vasta dimensão e que requerem a utilização de elevados investimentos à cabeça e a gestão de serviços especializados. Os autores ressalvam que, da utilização de Parcerias Público-Privadas, dificilmente resultarão em poupanças ao erário público, contrariamente ao que por vezes é referido como sendo a principal razão para o recurso a esta modalidade de contrato. A principal vantagem na utilização de Parcerias Público-Privadas consiste na tempestividade do investimento, que poderá mais facilmente ser assumido por uma entidade do setor privado, desonerando o erário público de proceder a elevados investimentos à cabeça, o que poderia ser gravoso para os cidadãos, pois o Estado teria de procurar formas de se financiar, eventualmente pelo endividamento ou pelo aumento dos impostos. No entanto, mesmo esta vantagem tem os seus pontos fracos, pois o parceiro privado terá de ser ressarcido pelo investimento e irá procurar a sua receita em futuras receitas de impostos ou em futuras receitas dos utilizadores, que deixam de reverter para os cofres do estado a longo prazo. Assim, não havendo vantagens financeiras na utilização de Parcerias Público-Privadas, a utilização desta forma de contratação deveria alicerçar-se na obtenção de ganhos de eficiência.

Sarmento (2010) reconhece a existência de um debate sobre o papel das Parcerias PúblicoPrivadas na criação de valor económico e utiliza um estudo de caso para comparar as opções Parceria Público-Privada ou a tradicional contratação de serviços - para determinar qual a opção mais rentável para o setor público. Analisando o caso das SCUT em Portugal, os resultados da análise indicam que o investimento teria sido bastante menos dispendioso em 2 a 3 mil milhões de euros se o setor público tivesse recorrido à contratação tradicional. $O$ autor conclui que este estudo de caso não permite a generalização sobre o papel das PPP na criação de valor económico, pois estudos de caso internacionais comprovam a existência desse mesmo valor. Mas o debate estende-se à fiabilidade dos resultados obtidos devido à metodologia utilizada no estudo de cada caso, admitindo-se que esta pode ter sido enviesada a favor do setor privado ou a favor do setor público. O autor conclui que é um facto que muitas Parcerias Público-Privadas falharam os seus propósitos, regressando o objeto contratual à guarda da gestão pública. 
A EPEC ${ }^{11}$ compilou um conjunto de dados de uma década relativos a contratos de Parcerias Público-Privadas que ocorrem nos países da União Europeia entre 2004 e 2013. Estes dados ${ }^{12}$ mostram na Figura 1, em baixo, que se verificou um crescimento em contratações de PPP de 2004 a 2007, e um decréscimo a partir de 2008.

Figura 1: Mercado Europeu das Parcerias Público-Privadas em biliões de euros

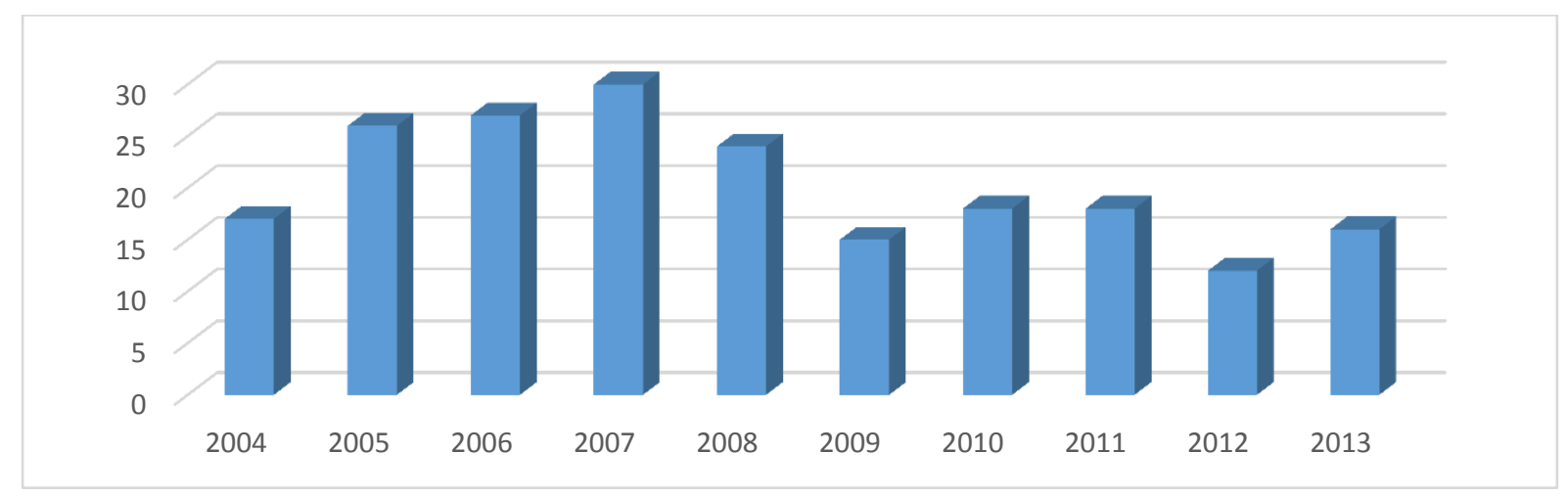

Fonte: EPEC

Em 2007 foram fechados cerca de 130 contratos de PPP na União Europeia, pelo valor aproximado de 30 mil milhões de euros. A Figura 2, em baixo, mostra que em 2013 o Reino Unido foi o maior contratante na União Europeia de Parcerias Público-Privadas tanto em número como em valor, com 31 contratos no valor aproximado de 6 mil milhões de euros. Segue-se a Itália que, em termos de valor apresenta 4,4 mil milhões de euros e a França, que apresenta 19 contratos. Os dados mostram ainda que em 2013, 14 países da União Europeia fecharam contratos de PPP. Portugal não se encontra entre este grupo de países, pois não fechou contratos de Parcerias Público-Privadas nesse ano, encontrando-se a analisar as parcerias existentes à data, como veremos adiante.

\footnotetext{
${ }^{11}$ EPEC - European PPP Expertise Centre.

12 Recolha de dados e metodologia de trabalhos: Dados compilados pela EPEC (European PPP Expertise Center) e recolhidos em várias fontes, nomeadamente Dealogic ProjectWare, InfraNews, Infrastructure Journal e Inspiratia. Os dados foram conferidos, sempre que possível com a base de dados do Banco Europeu do Investimento. A lista de PPP que constituem esta análise foi revista por colaboradores da EPEC e esta entidade alerta que os dados têm algumas limitações e que deverão ser utilizados com cautela. Os dados referem-se ao seguinte tipo de transações: PPP na União Europeia de valor igual ou superior a 10 milhões de Euros e que incluem a figura do financiamento do investimento, a partilha de risco entre os parceiros e cuja componente financeira esteja concluída no ano da análise. Os valores indicados referem-se ao somatório do investimento e débitos associados no momento da contratação da componente financeira do projeto e exclui contribuição de capitais públicos, logo, o valor total do financiamento poderá ser superior ao custo associado ao investimento.
}

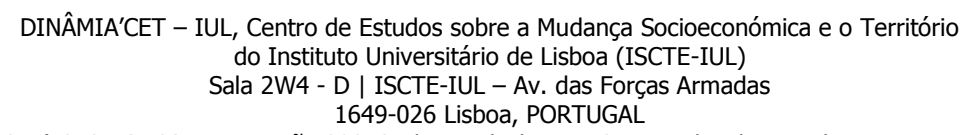


Figura 2: PPP Análise por país em milhões de euros (2013)

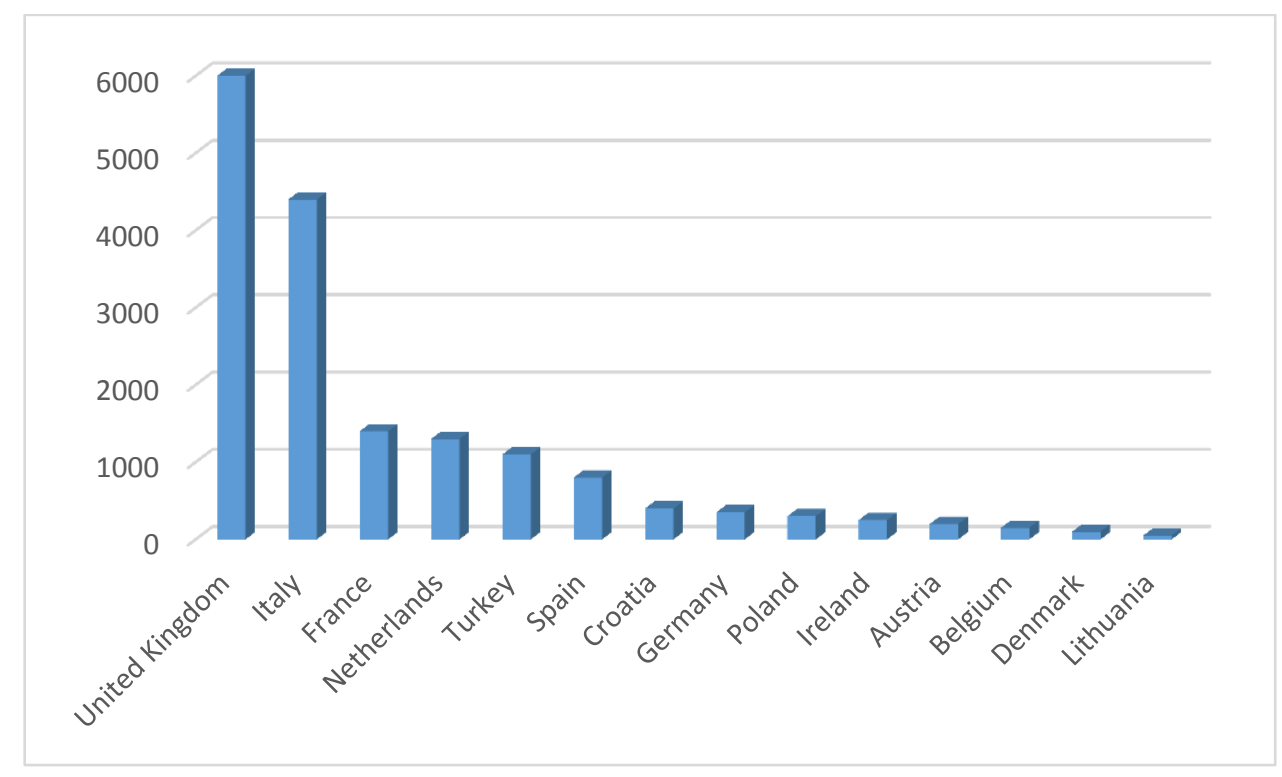

Fonte: EPEC

As áreas mais ativas em termos de valor onde se desenrolam as Parcerias Público-Privadas são o setor dos transportes, que representa mais de metade do valor total de investimentos, com 9,6 mil milhões de Euros em 2013 (Figura 3, em baixo), o que poderá ser consequência das políticas europeias para a área dos transportes, como sendo um dos pilares de crescimentos e desenvolvimento económico da União Europeia ${ }^{13}$.

${ }^{13}$ http://gef.eu/publication/eu-2012-priorities-transport-policy/, consultado em 15/01/2016.

"In its 2011 Roadmap to a Single European Transport Area, the Commission has addressed the following challenges for the future of European transport by 2050: 1) the need to complete the internal market for transport, especially by fully uniting the eastern and western parts of Europe; 2) the reduction of the EU transport sector's oil dependence; 3) a cut of at least 60\% of GHG emissions by 2050 with respect to 1990 required from the transport sector to limit climate change below $\left.2^{\circ} \mathrm{C} ; 4\right)$ a rethinking of mobility and investments in infrastructures in order to reduce congestion and minimise negative impacts of transport on the environment."

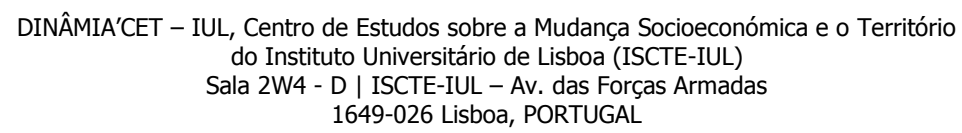


Figura 3: Valor dos contratos por setor, em milhões de euros (2013)

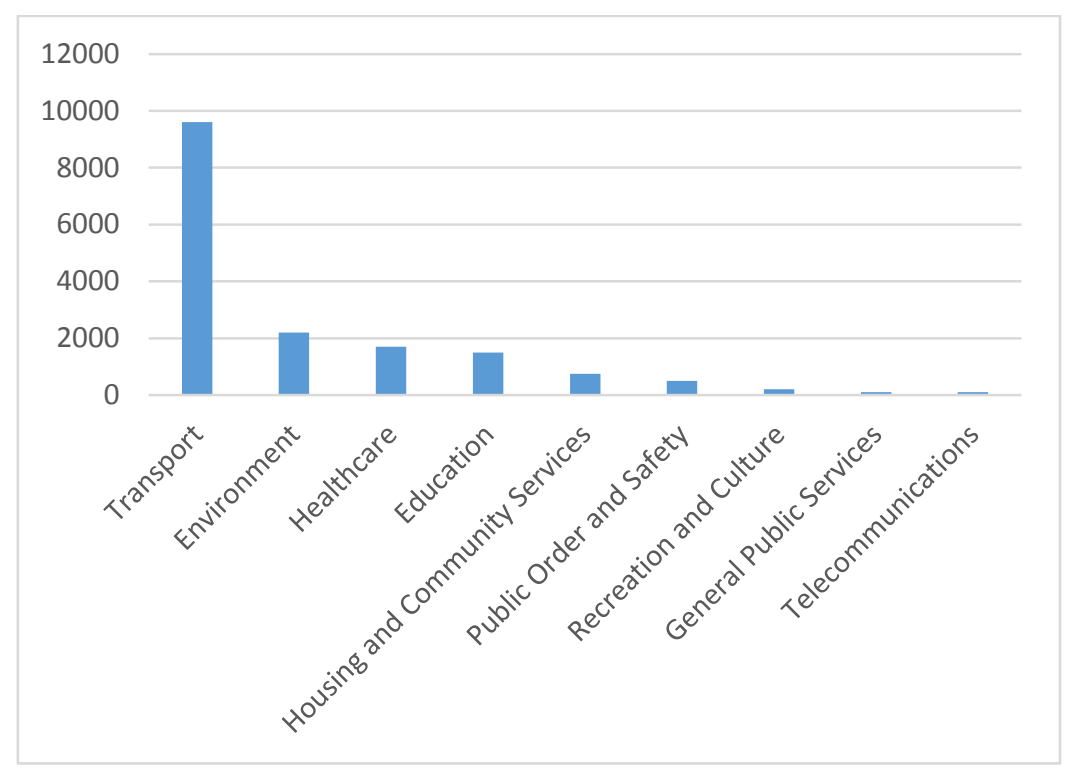

Fonte: EPEC

Dos 6 maiores projetos fechados em 2013, 5 situavam-se no setor dos transportes. Também o setor do ambiente revelou bastante atividade na área das Parcerias Público-Privadas em 2013, onde foram negociados 13 contratos no valor de 2,3 mil milhões de euros, a maioria dos quais se situou no Reino Unido (10 contratos). Esta atividade poderá dever-se à política ambiental seguida pela União Europeia como forma de atingir as metas para o desenvolvimento sustentado negociadas na conferência Rio+20) ${ }^{14}$. Segue-se o setor da saúde que concluiu 12 contratos em 2013 no valor total de 1,5 mil milhões de euros. O setor da educação foi aquele que movimentou um maior número de negociações, fechando 21 contratos em 2013.

As evidências mostram que a figura contratual de Parceria Público-Privada teve acolhimento nos países da União Europeia e que poderá mesmo ter sido impulsionado pelas políticas seguidas pela União Europeia, pois identifica-se a existência de PPP em diversas áreas onde as políticas públicas europeias têm sido mais enérgicas na última década, nomeadamente no setor dos transportes e do ambiente.

14 http://www.europarl.europa.eu/atyourservice/en/displayFtu.html?ftuId=FTU 5.4.1.html, consultado em $15 / 01 / 2016$.

"The EU also plays a key role in international environmental negotiations. For instance, at the 10th Conference of the Parties to the Convention on Biological Diversity, held in Nagoya (Japan) in 2010, the EU made a major contribution to achieving an agreement on a global strategy to halt the loss of biodiversity over the next ten years. Likewise, the Union participated in the decision to develop global Sustainable Development Goals (SDGs) for all countries which emerged from the 'Rio+20' conference on sustainable development held in 2012. Traditionally, the EU also has set standards during international climate negotiations under the United Nations Framework Convention on Climate Change (UNFCCC), for example by making unilateral commitments to reduce GHG emissions. Apart from global negotiations, the EU maintains partnership agreements and cooperation strategies with a number of countries and regions, e.g. within the European Neighbourhood Policy (Eastern and Mediterranean countries), as a means to address issues arising at the EU's external borders, including environmental issues such as water quality, waste management, air pollution or desertification."

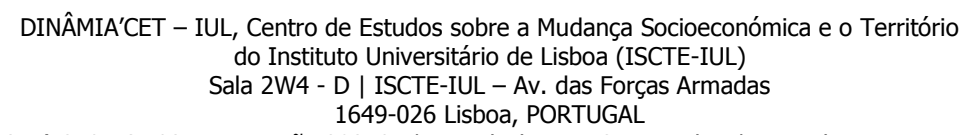




\section{O PAPEL DAS PARCERIAS PÚBLICO-PRIVADAS EM PORTUGAL}

Os dados institucionais ${ }^{15}$ recolhidos pela Direção-Geral do Tesouro e Finanças (DGTF) do Ministério das Finanças em valores atualizados, em 2012 mostram que as Parcerias Público-Privadas em Portugal "representam um encargo futuro elevado para as contas públicas". Em quatro anos, "entre 2008 e 2011, o montante dos encargos líquidos com as PPP quase quadruplicou, ascendendo a 1.823 milhões de euros no último ano. Em percentagem do PIB estes encargos evoluíram de aproximadamente 0,3\% em 2008 para 1,1\% em 2011. Deve ser realçado que o valor de 2011 representa um acréscimo de aproximadamente $25 \%$ face aos valores inicialmente previstos."

A DGTF não limitou o âmbito deste estudo sobre a situação das Parcerias Público-Privadas em Portugal ao presente e analisou o impacto futuro nas contas públicas em resultado das condições contratuais existentes no momento. Identificou que “(...) até 2040, existe um valor significativo de encargos brutos contratualizados, em particular no período 2015-2018, no qual se estima que estes ultrapassem os 2.000 milhões de euros por ano.

Como se pode observar, a maior parte do valor dos investimentos contratados diz respeito a infraestruturas rodoviárias, seguida das parcerias na área da saúde." Mantendo-se o cenário atual, o volume dos compromissos assumidos com a Parcerias Público-Privadas aumentará os encargos públicos a médio prazo, "uma vez que os encargos brutos estimados apresentam valores em torno de $1 \%$ do PIB previsto para os próximos anos".

O relatório elaborado pela DGTF estimava o valor dos encargos brutos futuros do Estado com os contratos de Parcerias Público-Privadas estabelecidos até 2012 em 24,4 mil milhões, sem considerar o valor das renegociações que estavam em curso na altura, representando 14,6\% do PIB previsto para o mesmo ano (Gráfico I, em baixo). Considerando o valor dos proveitos previstos, o valor dos encargos líquidos estimado era de 13,4 mil milhões de euros, o que representa 8,0\% do PIB para o corrente ano.

${ }^{15}$ Dados da DGTF para Portugal. Não incluem as Regiões da Madeira e dos Açores, nem incluem dados das autarquias locais. 
Gráfico 1: Valor atualizado dos encargos brutos com PPP de 2012 a 2040 (em milhões de euros do PIB previsto para 2012)

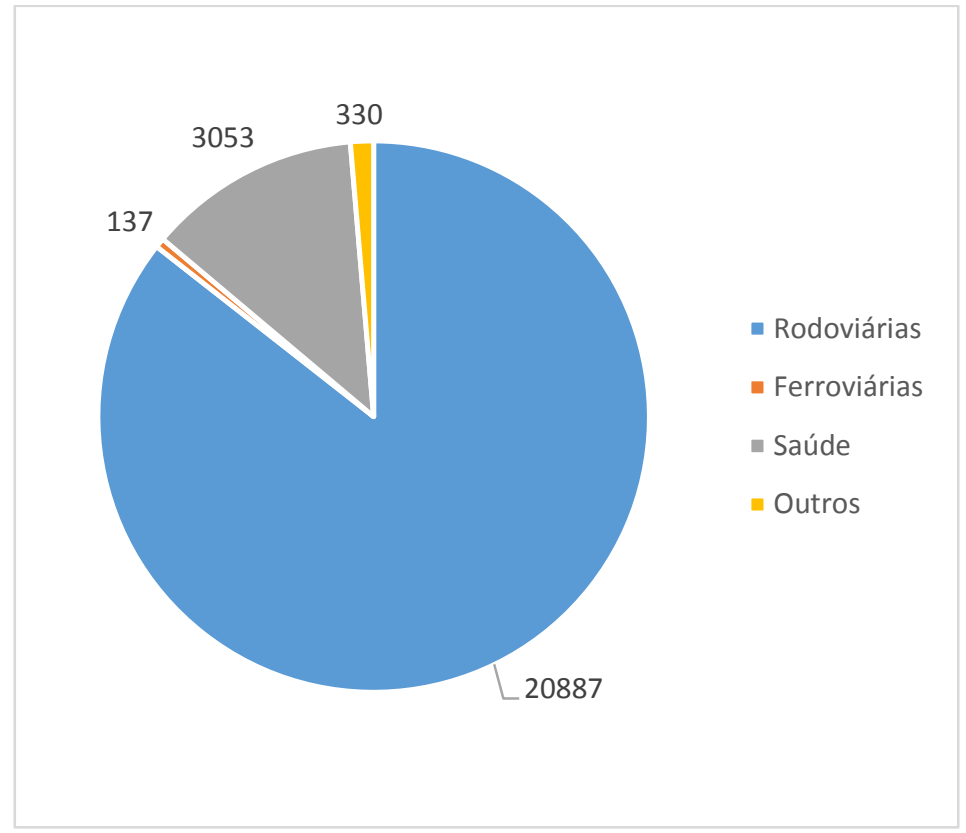

Fonte: Ministério das Finanças

Relativamente aos fatores de risco assumidos pelo setor público nas Parcerias PúblicoPrivadas, a DGTF, depois de se debruçar sobre as matrizes de risco associadas a cada contrato, salienta o risco da procura nas concessões das autoestradas, pois a falta de tráfego penaliza o Estado pela redução do volume de receita obtido.

Sobre os empréstimos concedidos pelo setor financeiro nacional às Parcerias PúblicoPrivadas, em maio de 2012 ascendia a 4,1 mil milhões de euros, $17 \%$ mais do que em finais de 2010, sendo a maturidade dos empréstimos bastante longa, entre 5 e 25 anos para cerca de $90 \%$ dos empréstimos. Os empréstimos concentram-se nos setores dos transportes, da construção e das atividades de consultoria e científicas. Também em maio de 2012 os empréstimos concedidos por entidades não residentes a Parcerias Público-Privadas eram de 3,8 mil milhões, dos quais mais de 76\% foi concedido pelo Banco Europeu de Investimento (BEI).

Pela análise destes dados, conclui-se que a aplicação das Parcerias Público-Privadas resultou no aumento do endividamento público, devido a compensações contingentes e à proliferação de contratos, e que virá a onerar os orçamentos de estado da próxima geração até 2040. Os dados não mostram se houve poupança para o Orçamento de Estado nos anos em que decorreram respetivamente a operação de cada uma das PPP, nem apresentam indicadores sobre a qualidade do serviço prestado. Veremos, seguidamente, a partir da análise da literatura dos autores que se debruçaram sobre o caso das PPP em Portugal se é possível extrair alguma conclusão sobre estas duas questões.

\footnotetext{
DINÂMIA'CET - IUL, Centro de Estudos sobre a Mudança Socioeconómica e o Território do Instituto Universitário de Lisboa (ISCTE-IUL)

Sala 2W4 - D | ISCTE-IUL - Av. das Forças Armadas 1649-026 Lisboa, PORTUGAL 
As Parcerias Público-Privadas ganharam importância em vários países da OCDE como modo alternativo de construção de infraestruturas na última década do século $\mathrm{XX}$ e na primeira década do século XXI. A análise efetuada aos países da OCDE mostra uma grande variedade de situações nas diferentes áreas de atuação pública, o que sugere a possibilidade de aprendizagem sobre a melhor forma de se conduzir uma Parceria Público-Privada com base nas diversas experiências existentes em vários países (Currestine et al., 2008). Reportando-se à situação de Portugal, os autores referem o défice orçamental estrutural existente desde finais do século XX, tendo o Conselho Europeu declarado por duas vezes, após a adoção do euro em 1999, que Portugal estava em situação de défice excessivo em 2002 e em 2005. Neste último ano, deu-se início a um conjunto de medidas estruturais de controlo orçamental e processual, que abrangeram as Parcerias Público-Privadas detidas pela administração pública local e pelas empresas públicas, considerando o potencial destas parcerias para a criação de responsabilidades futuras imputáveis ao estado. Os autores reconhecem que deverão ser tomadas medidas para o controlo desta forma de contratação, recomendando a revisão cuidadosa para garantir que os contratos das Parcerias Público-Privadas cumprem os testes de eficiência e que não aceitam riscos desnecessários, e recomendando também a discussão no Parlamento sempre que o setor público queira contratar uma nova PPP, como forma de garantir o envolvimento dos vários grupos políticos no processo. Foi ainda feita a recomendação de se garantir a transparência nas contas públicas sobre o papel das empresas públicas na ação governamental, dado o seu papel central na contratação de Parcerias Público-Privadas e considerando ainda a sua capacidade de endividamento e a possibilidade de onerarem o Orçamento de Estado e as gerações futuras.

Para Marques e Silva (2008), o aparecimento das Parcerias Público-Privadas em Portugal justifica-se pelo aumento da exigência dos níveis de qualidade dos serviços públicos conjugado com a limitação dos recursos público, que conduziu à procura de soluções alternativas às utilizadas no passado. A contratação de Parcerias Público-Privadas, já utilizada em vários países da União Europeia, pareceu ser a solução que se apresentava no momento, devido às características específicas desta forma de contratação. Debruçando-se sobre as concessões rodoviárias, o autor identifica três tipos de consequências emergentes dos problemas que surgiram nestas concessões, nomeadamente encargos adicionais para o estado resultantes da necessidade de reequilíbrios financeiros dos projetos, o enviesamento dos princípios de contratação e finalmente a ineficiência do controlo e fiscalização das concessões. Os problemas que estiveram na origem destas consequências resultaram da ausência de avaliação ambiental atempada, questões políticas relacionadas com a mudança de governo e a introdução de alterações às condições estabelecidas nos contratos, assim como limitações administrativas associadas ao processo de expropriação de terrenos e, finalmente, pela fraca preparação técnica dos concursos devido à ausência de avaliação de outras concessões e ainda em função de insuficiências na própria organização dos serviços públicos, resultando em falta de rigor na

\footnotetext{
DINÂMIA'CET - IUL, Centro de Estudos sobre a Mudança Socioeconómica e o Território do Instituto Universitário de Lisboa (ISCTE-IUL)

Sala 2W4 - D | ISCTE-IUL - Av. das Forças Armadas 1649-026 Lisboa, PORTUGAL 
definição dos requisitos técnicos, com impacto na qualidade do trabalho apresentado pelo concessionário. Por outro lado, a cadência a que foram lançados os contratos de concessão em Portugal não permitiu que se extraíssem lições ou boas práticas de contratos anteriores, tendo a experiência das Parcerias Público-Privadas em Portugal sido baseada no modelo inglês, cujas premissas de contratação baseadas na realidade económica, social e política diferem das existentes em Portugal. Finalmente, não estavam definidos os termos em que deveria decorrer a monitorização e controlo das Parcerias Público-Privadas nem quem iria realizar essa monitorização na perspetiva técnica e administrativo-financeira e como seria efetuada a avaliação de desempenho da concessão. $\mathrm{O}$ autor conclui que o estado não se pode demitir da responsabilidade das consequências resultantes da parceria por não ter regulado em função das discrepâncias identificadas no decurso do projeto.

Para Sarmento (2013), o papel das Parcerias Público-Privadas não se enquadra apenas pelas componentes financeiras da poupança, do financiamento ou da transferência do risco para outra entidade que não seja a Administração Pública, mas sim pelos ganhos de eficiência na prestação do serviço, sendo este o fator que traz um benefício comum aos parceiros. No entanto, foi a preponderância do setor financeiro em Portugal que levou a que o fator de investimento tivesse um maior peso na negociação com o parceiro privado em detrimento da partilha de risco como forma de redução do custo do financiamento, invertendo a lógica de funcionamento das Parcerias PúblicoPrivadas que deveria assentar na realização de ganhos associados à operação e ao risco associado a esta e não sobre o custo do investimento. Esta inversão de lógica leva o autor a questionar sobre a vantagem económica de se criarem Parcerias Público-Privadas. Para o autor, a assunção de riscos por parte do parceiro privado constitui uma forma de incentivo à eficiência do setor privado, pois de outro modo não se pode alegar que o setor privado é mais eficiente na gestão e manutenção de processos associados à sua área de conhecimento e atuação. Um outro aspeto patente na introdução do modelo contratual das Parcerias Público-Privadas por parte do governo consiste na manipulação das despesas no orçamento de estado, isto é, a utilização das PPP como instrumentos de desorçamentação, para evitar as limitações inerentes à despesa pública no momento da tomada da decisão, acabam por fazer com que o custo da parceria se projete em orçamentos públicos de anos futuros, por vezes com custos de valor incerto.

Destinadas a resolver problemas de finanças públicas, não foi ainda provado que as parcerias público-privadas representem um bom negócio a médio e longo prazo para o Estado (Lagoa et al., 2012: 344). A análise do setor da saúde em Portugal, revela que as PPP parecem ser um negócio mais lucrativo para as entidades financeiras do que para o Estado. Enquanto os bancos financiam a operação e cobram os serviços de gestão, pois a empresa líder da parceria também poderá pertencer a um grupo bancário, o Estado irá pagar por largos anos uma renda a uma empresa privada em troca da construção e gestão de hospitais. Utilizadas também na construção de autoestradas, pontes e outras

\footnotetext{
DINÂMIA'CET - IUL, Centro de Estudos sobre a Mudança Socioeconómica e o Território do Instituto Universitário de Lisboa (ISCTE-IUL)

Sala 2W4 - D | ISCTE-IUL - Av. das Forças Armadas 1649-026 Lisboa, PORTUGAL 
estruturas de transporte, além da assunção de eficiência superior dos operadores privados na construção e gestão de tais estruturas, o principal motor para o recurso às PPP assenta na possibilidade de construção rápida de infraestruturas sem afetar o atual défice orçamental (Lagoa et al., 2012: 260, 340). Em 2011, no contexto de uma profunda crise económico-financeira que deu origem a que o Estado português formalizasse um pedido de ajuda financeira à Troika, esta entidade propôs reformas nos contratos de parcerias público-privadas existentes devido ao seu peso e permanência na estrutura de custos do Orçamento de Estado (Lagoa et al., 2012: 335).

Assim, também no caso português não se encontram na literatura evidências de poupanças no Orçamento de Estado nem referências à qualidade do serviço prestado ao público pela Parcerias Público-Privadas. No entanto, pode-se concluir que muitas coisas podem correr mal na condução destas parcerias.

\section{PARCERIAS PÚBLICO-PRIVADAS - O QUE PODE CORRER MAL?}

Araújo e Sutherland (2010) apontam para o crescimento das Parcerias Público-Privadas como forma de rodear as pressões orçamentais dos governos e chamam a atenção para os riscos associados da utilização inapropriada desta relação contratual, como forma de desorçamentação. Os autores chamam a atenção para a não inclusão dos passivos contingentes nos orçamentos de estado e no impacto que esta omissão pode vir a ter a longo-prazo na sustentabilidade macroeconómica e na passagem de testemunho à próxima geração. Por outro lado, os benefícios da participação do setor privado não estão assegurados nas Parcerias Público-Privadas, dependendo da relação contratual estabelecida e da partilha de risco assumida entre ambos os parceiros.

Engel, Fischer e Galetovic (2010) apontam para o risco do custo da Parceira Público-Privada poder exceder o valor previsto para a participação financeira do governo, o que se pode dever a contratação inadequada, ao recurso a formas de investimento inadequadas ao projeto em causa ou à assunção de riscos externos não controláveis, ou ainda à contratação de incentivos para o parceiro privado assegurar inovações organizacionais e a manutenção da infraestrutura. Os autores apontam para um outro risco que se prende com a possível existência de débitos contingentes não identificados devidamente nas contabilidades do governo e do parceiro privado e que deveriam ser associados às receitas futuras da parceria, por forma a não impactarem negativamente os orçamentos de estado nem as despesas do parceiro privado.

Marques e Silva (2008) referem que nem sempre o desenvolvimento das Parcerias PúblicoPrivadas atinge os objetivos pretendidos, perdendo-se no tempo a noção de parceria onde deveria existir uma partilha de riscos, benefícios e responsabilidades.

As desvantagens das Parcerias Público-Privadas apontadas por Engel, Fischer e Galetovic (2010) consistem na forma como podem contornar as regras de registo contabilístico e ofuscar os

\footnotetext{
DINÂMIA'CET - IUL, Centro de Estudos sobre a Mudança Socioeconómica e o Território do Instituto Universitário de Lisboa (ISCTE-IUL)

Sala 2W4 - D | ISCTE-IUL - Av. das Forças Armadas 1649-026 Lisboa, PORTUGAL 
custos futuros e as possíveis contingências que advenham do objeto do contrato, escapando à regulação e ao controlo existente. Por outro lado, a complexidade das PPP requer um processo de engenharia financeira sofisticado.

Hemming (2006) identifica as condições contratuais como sendo o aspeto onde subjaz uma maior probabilidade de se ultrapassar os custos contratuais devido à possibilidade de renegociação no decurso do período de construção e operação do objeto do contrato, fator que poderá igualmente prejudicar a qualidade. $\mathrm{O}$ autor refere que a maior parte dos riscos associados a uma Parceria PúblicoPrivada deverá ser gerida pelo parceiro do setor privado, pois esta é a única forma de promover o incentivo para a construção de uma solução mais eficiente ao investimento público e este fator deveria ser primordial na tomada de decisão do governo sobre a constituição de uma Parceria PúblicoPrivada. A incerteza política e o empenho dos vários setores políticos em posição de formarem governo no futuro é um outro fator que pode prejudicar as condições e os resultados da parceria, que é um compromisso de longo prazo, podendo abalar a confiança entre os parceiros público e privado. A necessidade de se estabelecer canais de responsabilidade e de imputação de resultados é um fator decisivo na gestão de uma PPP, o que implica que a possibilidade de existência de corrupção no seio do parceiro público será um obstáculo ao sucesso da parceria. O mesmo argumento se aplica quando a decisão de contratar uma PPP se associa ao benefício de um parceiro específico ou de uma certa região, pondo em causa a eficiência, os ganhos e consequentemente a qualidade dos resultados da contratação. Este aspeto deverá ser mitigado de forma legislativa. Outro fator de risco é a ausência de competência no setor público para a gestão de parcerias com esta complexidade. Uma outra situação de risco é o tempo de maturidade da fase pré-contratual, que se afigura mais longa no setor público do que no setor privado, o que requer uma revisão dos processos administrativos e legais.

\section{PARCERIAS PÚBLICO-PRIVAdAS - O QUE CORREU MAL EM PORTUGAL}

Para Cruz e Marques (2012) a avaliação das vantagens da criação de uma Parceria PúblicoPrivada face às formas tradicionais de contratação deverá ser o ponto de partida para um investimento de grande envergadura. Os autores salientam como aspetos que correram mal nas parcerias existentes em Portugal a falta de transparência no processo de implementação e gestão, que precisa de ser melhorado, o tratamento contabilístico na perspetiva orçamental que omite os impactos futuros nos orçamentos de estado, as formas de contratualização, que deveriam ser revistas para permitir uma melhor utilização do erário público, onde ressaltam as renegociações existentes nas parcerias, pese embora estas sejam efetuadas para garantir um serviço adequado às necessidades atuais dos cidadãos contribuintes, as mesmas conduzem a um agravamento dos encargos públicos com consequências negativas nas Finanças Públicas e consequentemente, no endividamento público ou num possível

\footnotetext{
DINÂMIA'CET - IUL, Centro de Estudos sobre a Mudança Socioeconómica e o Território do Instituto Universitário de Lisboa (ISCTE-IUL)

Sala 2W4 - D | ISCTE-IUL - Av. das Forças Armadas 1649-026 Lisboa, PORTUGAL 
aumento da carga fiscal. Para os autores, revela-se indispensável a definição de instrumentos de controlo e gestão dos contratos que reduzam as ausências de informação, contrariem a possibilidade de cartelização no setor e que previnam o aparecimento de corrupção, tornando as decisões e as informações claras e transparentes.

O Tribunal de Contas, órgão de fiscalização das Administrações Públicas, tem vindo a efetuar ao longo do tempo diversas auditorias às concessões das Parcerias Público-Privadas. Na auditoria de maio de 2015 às Parcerias Público-Privadas Ferroviárias, o Tribunal de Contas identifica que “(...) a comunicação entre o concedente e as concessionárias tem sido deficiente e o Tribunal não encontrou evidências de que o Estado tenha sido diligente para a obtenção de acordos que sejam mais favoráveis para os interesses públicos em causa. (...) A deficiente comunicação do Estado com os parceiros privados, a demora e descontinuidade nos processos negociais afetam não só o relacionamento entre parceiros, mas também as condições de previsibilidade necessárias à boa execução dos contratos de concessão de serviço público."

O Tribunal de Contas acrescenta que, pela via fiscal, o cidadão, seja ou não utente do serviço de transporte ferroviário, suporta indiretamente os encargos do Estado com as concessões da REFER e da Fertagus, pois “(...) Na concessão Fertagus, a partir de 2011, o Estado concedente não tem suportado encargos diretos, mas apesar disso a existência do serviço continua indiretamente a consumir receitas fiscais. A REFER, parte do sector público, gestora da infraestrutura, e que consolida no Orçamento do Estado continua deficitária.” O Tribunal de contas acrescenta, na página 42 do relatório de auditoria que "(...) Na concessão MST, existem significativas compensações por défice de tráfego." Sobre a questão do custo direto do serviço público, o Tribunal de Contas faz uma referência à revisão tarifária no caso da Fertagus, indicando que a revisão de tarifas está prevista contratualmente e tem sido efetuada anualmente. No entanto, a obtenção de receita poderá estar comprometida devido ao clima de crise económica e à redução da procura do serviço por parte dos utentes. Para o caso da concessão MST, as condições estipuladas contratualmente relativamente à base tarifária média, não têm permitido alterações tarifárias.

\section{CONCLUSÃO}

O tema das Parcerias Público-Privadas tem gerado o debate, quer no meio tecnocrata, quer no meio académico, sobre o papel desta forma de contratação na criação de valor económico.

Alguns autores defendem que as PPP geram valor e outros defendem que a existência desta forma de contratação não se justifica pela criação de valor económico mas sim pela eficiência associada a uma melhor prestação de um serviço público. O financiamento dos investimentos elevados e de longa duração, assim como a futura obtenção de receitas para o governo, a gestão eficaz do parceiro privado e a sua capacidade de inovar são qualidade que conduzem ao acréscimo da

\footnotetext{
DINÂMIA'CET - IUL, Centro de Estudos sobre a Mudança Socioeconómica e o Território do Instituto Universitário de Lisboa (ISCTE-IUL)

Sala 2W4 - D | ISCTE-IUL - Av. das Forças Armadas 1649-026 Lisboa, PORTUGAL 
eficiência e que conduzem a um aumento na qualidade e / ou à redução dos custos dos serviços. Assim, as Parcerias Público-Privadas poderão ser uma boa forma de rentabilizar os recursos financeiros públicos.

Uma outra corrente de autores ressalva que a utilização de Parcerias Público-Privadas, dificilmente resultará em poupanças ao erário público, consistindo a sua principal vantagem na tempestividade do investimento, que poderá mais facilmente ser assumido por uma entidade do setor privado, desonerando o erário público de proceder a elevados investimentos à cabeça, o que poderia ser gravoso para os cidadãos, pois o Estado teria de procurar formas de se financiar, eventualmente pela via do endividamento ou pelo aumento dos impostos. Assim, não havendo vantagens financeiras na utilização de Parcerias Público-Privadas, a utilização desta forma de contratação deveria alicerçarse na obtenção de ganhos de eficiência.

Para Sarmento (2013), a preponderância do setor financeiro em Portugal levou a que o fator de investimento tivesse um maior peso na negociação com o parceiro privado, em detrimento da partilha de risco, como forma de redução do custo do financiamento, o que inverteu a lógica de funcionamento das Parcerias Público-Privadas, que deveria assentar na realização de ganhos associados à operação e ao risco associado a esta e não sobre o custo do investimento. Esta inversão de lógica leva o autor a questionar sobre a vantagem económica de se criarem Parcerias PúblicoPrivadas em Portugal.

Através da análise dos dados empíricos e da literatura não foi possível confirmar que as Parcerias Público-Privadas geram poupanças ao erário público ou que apresentam mais qualidade nos serviços prestados. Antes pelo contrário, o relatório da Direção-Geral do Tesouro e Finanças de 2012 e a auditoria do Tribunal de Contas de 2015 apontam para o aumento dos custos face ao contratado. Como sugestão, poderiam ser desenhados indicadores de fácil medição para aferir a qualidade dos serviços prestados e para a comparação dos custos, como por exemplo inquéritos à satisfação dos utilizadores e a construção de modelos financeiros para a comparação dos custos das PPP com os custos públicos em áreas semelhantes no passado, embora anteveja algumas dificuldades na construção deste último, considerando as limitações da ótima orçamental utilizada na contabilidade pública. Uma outra preocupação dos autores, patente na introdução do modelo contratual das Parcerias Público-Privadas por parte do governo, consiste na possível manipulação das despesas no Orçamento de Estado com a utilização das PPP como instrumentos de desorçamentação, para evitar as limitações inerentes à despesa pública no momento da tomada da decisão. Esta lógica de utilização das PPP faz com que o custo da parceria se projete em orçamentos públicos de anos futuros, por vezes com valores incertos.

Desorçamentação, oneração das gerações futuras, contratação inadequada, perda de confiança na relação de parceria, complexidade no acompanhamento dos contratos, facilidade em ofuscar o

\footnotetext{
DINÂMIA'CET - IUL, Centro de Estudos sobre a Mudança Socioeconómica e o Território do Instituto Universitário de Lisboa (ISCTE-IUL)

Sala 2W4 - D | ISCTE-IUL - Av. das Forças Armadas 1649-026 Lisboa, PORTUGAL 
registo contabilístico dos valores em dívida na contabilidade pública, probabilidade de renegociação, incerteza política que pode levar à alteração do objeto contratual, possibilidade de existência de corrupção, falta de competência no parceiro público para o acompanhamento dos contratos, inércia da administração pública, são algumas das preocupações evocadas pelos diversos autores, nacionais e internacionais, e também pelos organismos públicos de controlo e fiscalização que se debruçaram sobre o tema das PPP em Portugal, que mostram o quanto ainda há por fazer nesta matéria para melhor se conhecer a realidade das Parcerias Público-Privadas e evitar que se voltem a cometer os erros do passado em situações futuras. Para já, dois desafios se colocam no futuro: o que fazer com as PPP existentes e decidir se a utilização de PPP deverá ser abandonada no futuro como instrumento político de investimento público. 


\section{REFERÊNCIAS}

ARAÚJO, S., Sutherland, D. (2010). Public-private Partnerships and Investment in infrastructure. Economics department working papers, 803, OECD.

BOWMAN, A., et al. (2015). What a Waste: Outsourcing and How it Goes Wrong. Manchester. Manchester University Press.

CRUZ, C. O., Marques, R. C. (2012). O Estado e as Parcerias Público-Privadas. Lisboa. Edições Sílabo.

CURRISTINE, T. et al. (2008). Budgeting in Portugal. OECD journal on Budgeting, 3/2008, OECD.

ENGEL E. et al. (2010). The economics of infrastructure finance: Public-Private Partnerships versus public provision. Public and private financing of infrastructure, Evolution and economics of private infrastructure finance, EIB Papers, 15, 1

FERNANDO, H. (2013). Um contributo para análise das Parcerias Público-Privadas rodoviárias em Portugal. Dissertação do Mestrado de Economia / Área de Especialização - Regulação e Concorrência. Faculdade de Economia da Universidade do Porto.

KAPPELER, A., Nemoz, M. (2010), Public-Private Partnerships in Europe - Before and during the recent financial crisis, Economic and Financial Report, July 2010, European Investment Bank Papers.

LAGOA, S., Leão, E., Paes Mamede, R. and Barradas, R. (2013), Report on the financial system in Portugal, FESSUD Studies in Financial Systems No. 9, 2013.

MARQUES, R. C., Silva, D. (2008). As Parcerias Público-Privadas em Portugal. Lições e Recomendações. Revista de Estudos Politécnicos, VI, 10.

MARZETTI, G. V. (2006). Structural change and service outsourcing. An application to some OECD countries. _some_OECD_countries, consultado em 11/01/2016. 
SARMENTO, J. M. (2010). Do Public-Private Partnerships Create Value for Money for the Public Sector? The Portuguese Experience. OECD Journal on Budgeting, 1. OECD.

SARMENTO, J. M. (2013). Parcerias Público-Privadas. Lisboa. Fundação Francisco Manuel dos Santos.

VALILA, T. et al. (2005), Roads on a Downhill? Trends in EU Infrastructure Investment. European Investment Bank Papers, Vol.10, 1.

WEIHE, G. (2006). Public-Private Partnerships: Addressing a Nebulous Concept. International Center for Business and Politics, Working Paper 16, Copenhagen Business School.

\section{Outras publicações consultadas:}

Auditoria às PPP Ferroviárias, Tribunal de Contas, Relatório n. ํ 11/2015, 2. ${ }^{a}$ Secção, maio 2015.

Livro verde sobre as parcerias público-privadas e o direito comunitário em matéria de contratos públicos e concessões, COM (2004), 327 Final, Bruxelas, 30/04/2004.

Market Update, Review of the European PPP Market in 2013, European PPP Expertise Center $(\mathrm{EPEC})^{16}$

Parcerias Público-Privadas e Concessões, Relatório 2012, Direção-Geral do Tesouro e Finanças, Ministério das Finanças, agosto 2012.

Public-Private Partnerships, Hemming, Richard Fiscal Affairs Department, International Monetary Fund (IMF), Realizing the Potential for Profitable Investment in Africa, High-Level Seminar organized by the IMF Institute and the Joint Africa Institute, Tunis, Tunisia, February28-March 1, 2006.

The 2009 Outsourcing World Summit, International Association of Outsourcing Professionals (IAOP).

${ }^{16}$ O Centro Europeu de Especialização das PPP (EPEC - European PPP Expertise Centre) foi criado em 2008 numa iniciativa conjunta entre o Banco Europeu de Investimento, a Comissão Europeia, os Estados Membros da União Europeia, os estados candidatos ao espaço europeu e ainda alguns outros estados. Para mais informações sobre a EPEC e os seus membros, consultar o site da organização: www.eib.org/epec. 